\title{
Study on the Thin Plate Model with Elastic Foundation Boundary of Overlying Strata for Backfill Mining
}

\author{
Dongdong Chen $\mathbb{D}^{1},{ }^{1}$ Xiaoyu Wu $\mathbb{D}^{1},{ }^{1}$ Shengrong Xie $\mathbb{D}^{1},{ }^{1}$ Yanding Sun, ${ }^{1}$ Qing Zhang, \\ En Wang, ${ }^{1}$ Yaohui Sun, ${ }^{1}$ Long Wang $\mathbb{D},{ }^{1}$ Hui Li $\mathbb{D},{ }^{1}$ Zaisheng Jiang, ${ }^{1}$ and Xiaowei $W u^{2}$ \\ ${ }^{1}$ School of Energy and Mining Engineering, China University of Mining \& Technology, Beijing 100083, China \\ ${ }^{2}$ Yongding Zhuang Mine, Datong Coal Mine Group, Datong 037024, China \\ Correspondence should be addressed to Shengrong Xie; xsrxcq@163.com
}

Received 15 December 2019; Accepted 13 February 2020; Published 17 March 2020

Academic Editor: Richard I. Avery

Copyright (c) 2020 Dongdong Chen et al. This is an open access article distributed under the Creative Commons Attribution License, which permits unrestricted use, distribution, and reproduction in any medium, provided the original work is properly cited.

\begin{abstract}
In order to better study the movement principles of overlying strata during backfill mining, we established a thin plate model on an elastic foundation with elastic foundation boundary of the main roof. And by the finite difference method, the variation principles of the main roof s principal moments and maximum subsidence $\omega_{0}$ with the elastic foundation coefficient $k_{1}$ of the coal seam, the elastic foundation coefficient $k_{2}$ of backfill body, the thickness $h$, Young's modulus $E$, and Poisson's ratio $\mu$ of main roof are calculated and studied. Using these calculations, we were able to determine that the main roof had three principal bending moment extreme points, including $M_{\mathrm{zz}}$ in backfill areas, $M_{c}$ of the long side area, and $M_{d}$ of the short side area. The distance $L_{c}$ of $M_{c}$ advancing coal wall continuously increased with the increase in $k_{2}$, while the principal moment of main roof's middle area decreased with an increase in $k_{2}$; when $k_{2}$ became larger, the maximum principal moment in the midpoint of main roof transferred to the surrounding and the maximum principal moments was in four-corner area; $M_{c}$ and $M_{d}$ decreased with an increase in $k_{2}$, and $M_{d}$ was more sensitive to $k_{2}$ than $M_{c}$; and $M_{d}$ decreased significantly with the increase in $k_{2}$. $L_{c}$ continuously decreased with the increase in $k_{1}$, while $M_{c}, M_{d}$ and $M_{\mathrm{zz}}$ increased with the increase in $k_{1}$ and the reduced amplitude of $M_{\mathrm{zz}}$ was the minimum. The effect of $\mu$ on principal bending moments and $\omega_{0}$ was very small; The growth rate of $M_{\mathrm{zz}}$ was the largest when $E$ or $h$ increased. $M_{d}$, $M_{\mathrm{zz}}$, and $L_{c}$ remained unchanged when $k_{1}, k_{2}$, and Young's modulus $E$ of the main roof increased while the ratio value remained constant $\left(k_{1} / k_{2} / E\right)$. Finally, the theoretical calculations were applied to the I26 backfill working face in the Xingdong mine to calculate the final subsidence amounts of the main roof. Field observations and theoretical calculations were about $48 \mathrm{~mm}$, verifying the method's applicability.
\end{abstract}

\section{Introduction}

Strata movement gradually develops on the surface after underground coal seam mining, causing surface subsidence, destruction of ground facilities, and so on. Solid backfill mining, paste backfill mining, high-water backfill mining, and other backfill mining methods are commonly used to prevent surface subsidence caused by underground mining. Qian et al. [1] put forward the concept of green mining in coal mine and expounded the basic methods of mining settlement and backfilling control. Wu et al. [2], through image algorithms and so on, analyzed the mining landscape changes before and after subsidence with the support of GIS technology. According to the characteristics of mining subsidence, Jung et al. studied the comprehensive prediction and calculation methods related to mining subsidence, and so on [3-9]. In view of the subsidence characteristics of the surface steps caused by the mining of the shallow and extra thick coal seam, Ju and $\mathrm{Xu}$ [10] put forward three possible control methods for surface stepped subsidence. Based on the field investigation and study of overburden damage in ultra-thick coal seam mining, the statistical formula was presented to estimate the maximum heights of failure zone in the LTCC operation [11]. The characteristics of displacement and ground subsidence caused by underground mining are studied by means of remote sensing and 
Geographic Information System [12-14]. Li et al. studied the mechanical characteristics of the gangue filling body, the mechanical and geometric characteristics of the hydraulic support for gangue filling, and the characteristics of the mining pressure in the solid filling face; they obtained that the solid backfilling method was an effective method to prevent hard-roof-induced face bursts, and the equivalent mining height model is capable of predicting surface deformation [15-20]. Benzaazoua et al. studied, respectively, the hardening process of cemented backfill, the preparation, microstructure characteristics, mechanical parameters, and backfilling technology of the paste backfill materials [21-24]. Based on the basic mechanical experiments of ultra-highwater materials, Ding et al. [25] found that it was good backfilling material. Yan et al. [26] put forward the pump filling technology of ZKD high-water quick-setting material, which was effectively applied to engineering practice. Feng et al. [27] introduced four kinds of backfilling methods for goaf with high water content materials and analyzed the advantages and disadvantages of each method.

There have been many studies on the backfill mining process and issues that may arise. Zhang et al. [28] analyzed the interaction between the backfilling body and overburden strata in a fully mechanized backfilling mining face. Miao et al. [29] proposed the beam model on an elastic foundation with a fixed boundary condition to study the relationship between subsidence of the main roof and Young's modulus of backfill body. Chen et al. [30] built a beam model on an elastic foundation with an elastic foundation boundary to analyze the variation of the main roof's maximum subsidence with Young's modulus of backfill body and elastic foundation coefficient of coal seam. Li et al. [31] proposed a thin plate model on an elastic foundation of the main roof with a fixed boundary condition to study the variation of the main roof's subsidence and maximum tensile stress with an elastic foundation coefficient of the backfill body. Huang et al. [32] analyzed overlying strata movement in backfill mining using a similar physical simulation, and although these results are beneficial for scientific backfill mining, there are specific scenarios that they are applicable. The beam model in backfill mining is only suitable for roof mechanics analysis of the middle area in the working face with large length-width ratio.

The thin plate model with the main roof being elastic and fixed boundary condition for backfill mining simplifies the main roof in order for it to be a fixed boundary condition. However, the main roof is bound to sink in the coal seam support area when the coal seam is thick and soft, making the fixed boundary condition unsuitable. The Winkler elastic foundation model should therefore be considered because of the weak shear-bearing capacity and non-deformability of the coal seam [33]. The main roof can then be regarded as an elastic foundation, and the elastic foundation model is able to analyze its mechanics and displacement characteristics during backfill mining.

Here, we established a thin plate model on elastic foundation of the main roof with an elastic foundation boundary to study the variations of the internal force field and displacement field with various elastic foundation coefficients of the backfill body, elastic foundation coefficients of the coal seam, thicknesses of main roof, Young's modulus of the main roof, and Poisson's ratio of the main roof, and the fracture position and fracture conditions of the main roof were then determined and compared. Finally, a determination method for the elastic foundation coefficient of the backfill body is proposed in this paper. These theoretical calculations were then verified using the 126 mining face from Xingdong coal mine. These results have practical value in further developments in backfill mining technology.

\section{The Thin Plate Model on Elastic Foundation with the Elastic Foundation Boundary in Backfill Mining}

2.1. The Actual Surrounding Rock Condition of the Main Roof in Backfill Mining. The main roof is clamped between the overlying strata and immediate roof after mining. Due to the large compressive deformation and the weak shear-bearing capacity of the coal seam, the coal seam is best represented by the Winkler elastic foundation model. Similarly, the backfill body is also best represented by the Winkler elastic foundation model. Figure 1 shows the surrounding rock relationship during backfill mining.

\subsection{Mechanical Hypothesis Condition of the Main Roof in Backfill Mining}

2.2.1. Hypothesis of Elastic Foundation Boundary. For this study, the coal seam is analyzed using the Winkler elastic foundation model. The displacement of the main roof is mainly limited by the immediate roof and coal seam. In general, Young's modulus of the coal seam is much lower than that of the main roof and immediate roof; therefore, the coal seam is the main factor that limits the displacement of the main roof. The elastic foundation coefficient $k_{0}$ can be derived from equation (1) and is given by

$$
k_{0}=\frac{E_{1} E_{0}}{E_{1} h_{0}+E_{0} h_{1}} \approx \frac{E_{1}}{h_{1}}=k_{1},
$$

where $k_{0}$ is the composite elastic foundation coefficient of the immediate roof and coal seam; $k_{1}$ is the elastic foundation coefficient of the coal seam; $h_{0}$ is the thickness of the immediate roof; $E_{0}$ is Young's modulus of the immediate roof; $h_{1}$ is the thickness of the coal seam; $E_{1}$ is Young's modulus of the coal seam.

2.2.2. Hypothesis of Elastic Foundation of the Backfill Body. Solid backfill material, paste backfill material, and highwater backfill material approximately satisfy the Winkler elastic foundation model.

2.2.3. Dimension Requirement of the Elastic Thin Plate of the Main Roof. In order to satisfy the requirements to be considered a "thin plate," the dimensions of the roof must meet the requirement of 


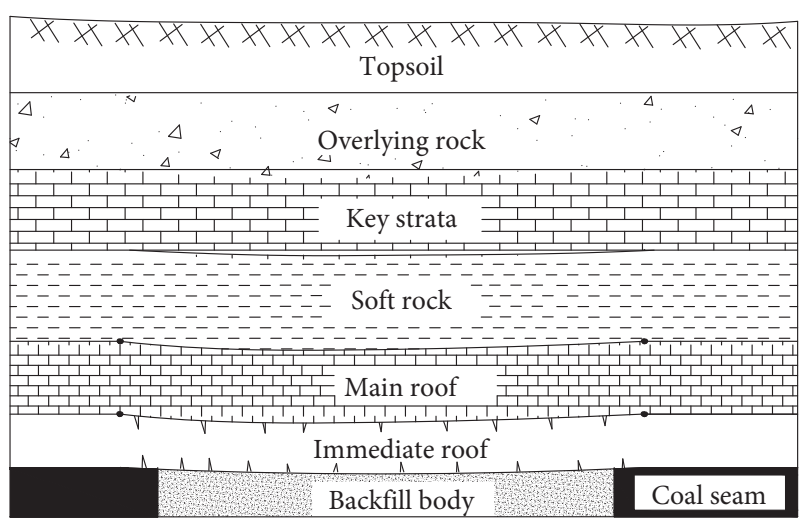

FIGURE 1: Depiction of the surrounding rock in backfill mining.

$$
\left(\frac{1}{8} \sim \frac{1}{5}\right) \geq \frac{h}{L} \geq\left(\frac{1}{100} \sim \frac{1}{80}\right),
$$

where $h$ is the thickness of the plate; $L$ is the short side length of the plate.

When $h$ and $L$ of the plate satisfy equation (2), the plate can be seen as a thin plate.

In general, the ratio of the thickness of the roof to the short side length satisfies equation (2); that is, the main roof satisfies dimension requirements of the elastic thin plate.

\subsection{Mechanical Model of the Thin Plate on Elastic Foundation with Elastic Foundation Boundary in Backfill Mining}

2.3.1. Mechanical Model. The mechanical model of a thin plate on an elastic foundation with an elastic foundation boundary of a main roof in backfill mining is shown in Figure 2.

The rectangle area $\mathrm{ABCD}$ is the backfill area $S_{2}$. The length of $\mathrm{AB}$ is $2 a$ and the length of $\mathrm{AD}$ is $2 b$. A coordinate system is established by using the midpoint of the main roof on the backfill body as the origin. Area $S_{1}$ of the main roof, which is outside of $A B C D$ and inside of $A_{1} B_{1} C_{1} D_{1}$, is approximately the clamping area of the elastic layer. The displacement of the main roof in area $S_{1}$ is mainly determined by the stiffness of the coal seam. The load carried by the main roof is $q_{0}$.

2.3.2. Deflection Equation. According to the theory of a plate [34-36], the partial differential equation of the deflection of the main roof in an elastic foundation area $S_{1}$ can be defined as

$$
\frac{\partial^{4} \omega_{1}}{\partial x^{4}}+2 \frac{\partial^{4} \omega_{1}}{\partial x^{2} \partial y^{2}}+\frac{\partial^{4} \omega_{1}}{\partial y^{4}}=\frac{1}{D}\left(-k_{1} \omega_{1}\right),
$$

where $\omega_{1}$ is the deflection function of the main roof in the area $S_{1}$; and $k_{1}$ is the elastic foundation coefficient of the coal seam. The stiffness of a thin plate is $D=E h^{3} /\left(12-12 \mu^{2}\right)$, where $E$ is Young's modulus of the main roof; $h$ is the thickness of the main roof; and $\mu$ is Poisson's ratio of the main roof.

The partial differential equation of deflection of the main roof in the backfill area $S_{2}$ can be defined as

$$
\frac{\partial^{4} \omega_{2}}{\partial x^{4}}+2 \frac{\partial^{4} \omega_{2}}{\partial x^{2} \partial y^{2}}+\frac{\partial^{4} \omega_{2}}{\partial y^{4}}=\frac{1}{D}\left(q_{0}-k_{2} \omega_{2}\right),
$$

where $\omega_{2}$ is the deflection function of the main roof in area $S_{2} ; q_{0}$ is the load carried by the main roof; and $k_{2}$ is the elastic foundation coefficient of backfill body.

\subsubsection{Boundary Conditions}

(1) Continuous Boundary Condition. Edges AB, BC, CD, and $\mathrm{AD}$ are the main roof's interface between the coal body and the backfill body. Therefore, deflection, rotation angle, bending moment, and shear force are the same on the interface, and a continuous condition can be achieved by combining all the relevant equations as equations (5) and (6). A continuous boundary condition for the main roof can, therefore, be expressed as

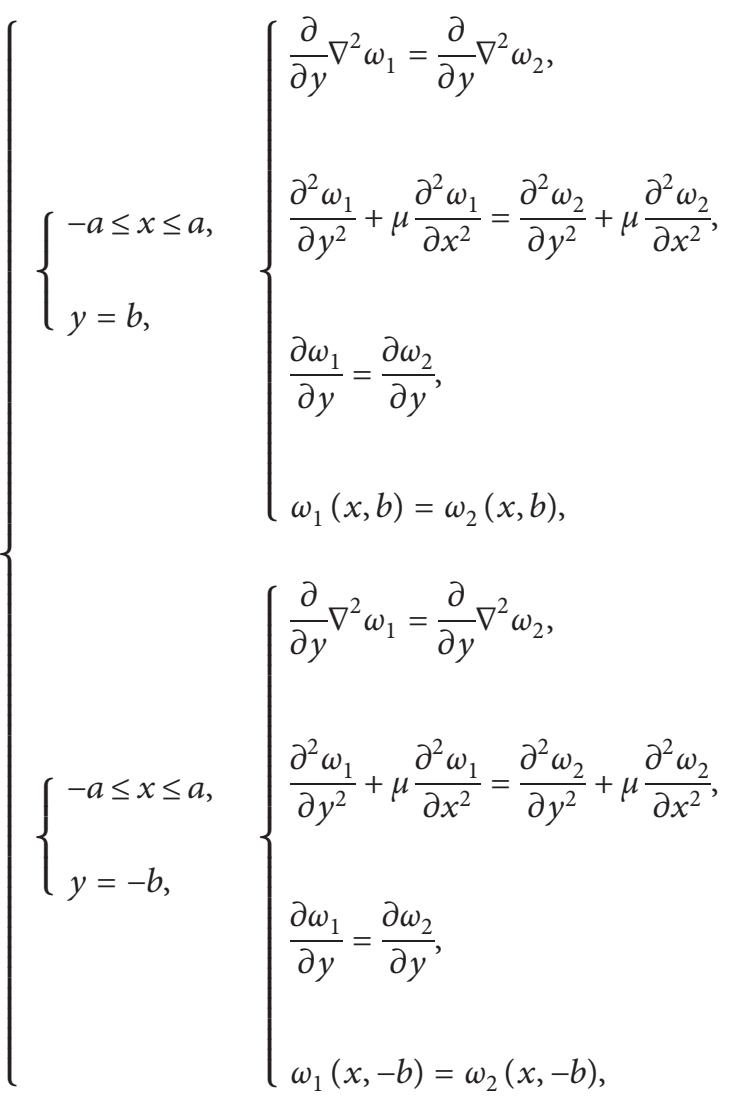




$$
\left\{\begin{array}{l}
\left\{\begin{array} { l } 
{ - b \leq y \leq b , } \\
{ x = a , }
\end{array} \left\{\begin{array}{l}
\frac{\partial}{\partial x} \nabla^{2} \omega_{1}=\frac{\partial}{\partial x} \nabla^{2} \omega_{2} \\
\frac{\partial^{2} \omega_{1}}{\partial x^{2}}+\mu \frac{\partial^{2} \omega_{1}}{\partial y^{2}}=\frac{\partial^{2} \omega_{2}}{\partial x^{2}}+\mu \frac{\partial^{2} \omega_{2}}{\partial y^{2}} \\
\frac{\partial \omega_{1}}{\partial x}=\frac{\partial \omega_{2}}{\partial x} \\
\left\{\begin{array}{l}
\omega_{1}(a, y)=\omega_{2}(a, y) \\
x=-a,
\end{array}\right.
\end{array}\right.\right. \\
\frac{\partial}{\partial x} \nabla^{2} \omega_{1}=\frac{\partial}{\partial x} \nabla^{2} \omega_{2} \\
\frac{\partial^{2} \omega_{1}}{\partial x^{2}}+\mu \frac{\partial^{2} \omega_{1}}{\partial y^{2}}=\frac{\partial^{2} \omega_{2}}{\partial x^{2}}+\mu \frac{\partial^{2} \omega_{2}}{\partial y^{2}} \\
\frac{\partial \omega_{1}}{\partial x}=\frac{\partial \omega_{2}}{\partial x}, \\
\omega_{1}(-a, y)=\omega_{2}(-a, y)
\end{array}\right.
$$

(2) Boundary Condition. $\mathrm{A}_{1} \mathrm{~B}_{1}$ length is $2 x_{0} \cdot \mathrm{A}_{1} \mathrm{D}_{1}$ length is $2 y_{0}$ (refer to Figure 2). At an infinite distance from the backfill area $S_{2}$, the mining effect is very small. Therefore, the deflection and rotation angle of the main roof are both zero and satisfy the fixed boundary conditions at an infinite distance from the backfill area $S_{2}$. The fixed boundary condition can then be defined as

$$
\left\{\begin{array}{l}
\left\{\begin{array} { l } 
{ x = - x _ { 0 } \rightarrow - \infty , } \\
{ - y _ { 0 } \leq y \leq y _ { 0 } , }
\end{array} \left\{\begin{array}{l}
x=x_{0} \rightarrow+\infty, \\
\left\{\begin{array}{l}
y=-y_{0} \rightarrow-\infty, \\
-y_{0} \leq y \leq y_{0}, \\
\left\{\begin{array}{l}
y x \\
y=0,
\end{array} \quad \frac{\partial \omega_{1}}{\partial x}=0\right.
\end{array}\right. \\
\left\{\begin{array}{l}
y=y_{0} \leq x \leq x_{0}, \\
\{+\infty,
\end{array} \quad \omega_{1}=0, \frac{\partial \omega_{1}}{\partial y}=0\right. \\
-x_{0} \leq x \leq x_{0},
\end{array} \quad \omega_{1}=0, \frac{\partial \omega_{1}}{\partial y}=0\right.\right.
\end{array}\right.
$$

\section{The Finite Difference Method for Solving the Partial Differential Equations}

As mentioned above, it is extremely difficult to obtain the exact solutions of the above partial differential equations, but the approximate solutions satisfy engineering and practical mining requirement. The finite difference method is an effective method to obtain the approximate solutions of differential equations [37-39].

\subsection{The Finite Difference Method}

3.1.1. The Nodal Layout of the Difference Equation. According to the finite difference theory, the difference equation involving 13 nodes is needed to solve the partial differential equation [34].

The difference grid layout of 13 nodes is shown in Figure 3. $\Delta x=\Delta y=d$ is the nodal space. Point $J_{0}$ is a feature node. Deflection of point $J_{0}$ is expressed as $\omega_{i j}$. Numbers of the remaining nodes are determined by the intersection of the vertical and horizontal lines (refer to Figure 3).

3.1.2. The Difference Equations of the Partial Differential Equations. Combining with the difference grid layout and the finite difference method of the partial differential equations (refer to Figure 3), the difference equations of the partial differential equations (3) and (4) at feature node $J_{0}$ can be obtained by

$$
\begin{aligned}
& \left(20+d^{4} \frac{k_{1}}{D}\right) \omega_{i j}-8\left(\omega_{i+1, j}+\omega_{i-1, j}+\omega_{i, j+1}+\omega_{i, j-1}\right) \\
& +2\left(\omega_{i+1, j+1}+\omega_{i+1, j-1}+\omega_{i-1, j+1}+\omega_{i-1, j-1}\right) \\
& +\omega_{i+2, j}+\omega_{i-2, j}+\omega_{i, j+2}+\omega_{i, j-2}=0
\end{aligned}
$$

where $d$ is the nodal space; $\omega_{i j}, \omega_{i+1, j}, \omega_{i-1, j}, \omega_{i, j+1}, \omega_{i, j-1}$, $\omega_{i+1, j+1}, \omega_{i+1, j-1}, \omega_{i-1, j+1}, \omega_{i-1, j-1}, \omega_{i+2, j}, \omega_{i-2, j}, \omega_{i, j+2}$ and $\omega_{i, j-2}$ are nodal deflection, respectively (refer to Figure 3 ).

$$
\begin{aligned}
& \left(20+d^{4} \frac{k_{2}}{D}\right) \omega_{i j}-8\left(\omega_{i+1}+\omega_{i-1, j}+\omega_{i, j+1}+\omega_{i, j-1}\right) \\
& +2\left(\omega_{i+1 j+1}+\omega_{i+1, j-1}+\omega_{i-1, j+1}+\omega_{i-1, j-1}\right)+\omega_{i+2, j} \\
& +\omega_{i-2, j}+\omega_{i, j+2}+\omega_{i, j-2}=\frac{q_{0} d^{4}}{D} .
\end{aligned}
$$

\subsubsection{The Difference Equations of Boundary Condition.} Theoretically, the exact fixed boundary condition can be satisfied when $x_{0}$ and $y_{0}$ approach infinity (refer to equation (7)), but the finite difference method cannot calculate this infinite region. Actually, when the outer boundary is three times the maximum length of the mining area $\left(y_{0}=x_{0}=3 \max \{2 a, 2 b\}\right)$, the influence of mining on this boundary is very weak, which approximately satisfies both the fixed boundary condition and engineering requirements. Nodal space $d$ is taken as $0.2 \mathrm{~m}$. The difference equations of the boundary condition in feature node $J_{0}$ can be expressed as 


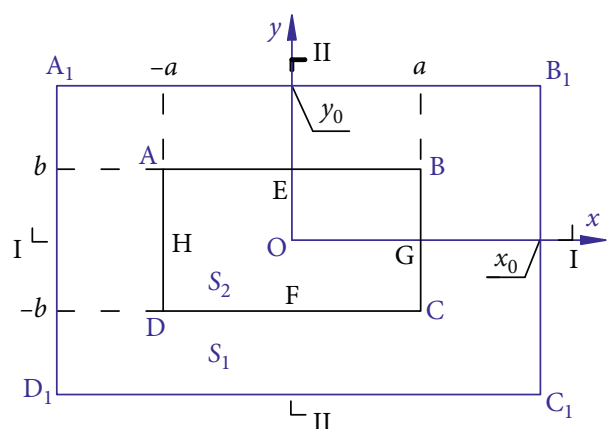

(a)

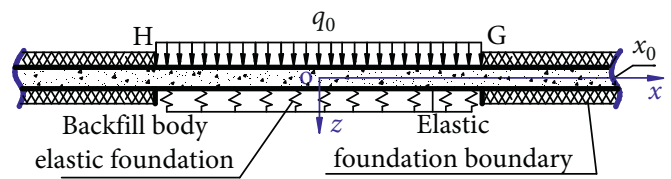

(b)

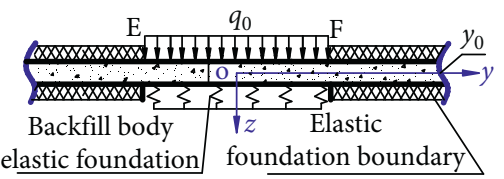

(c)

FIGURE 2: The thin plate model on an elastic foundation with an elastic foundation boundary. (a) Vertical view; (b) I-I section plane; (c) II-II section plane.

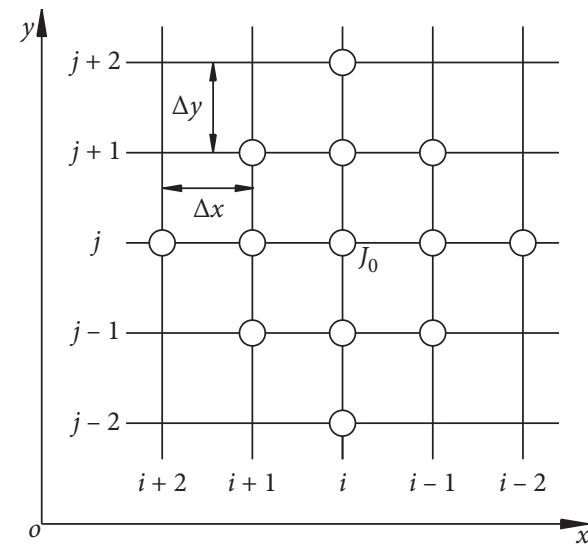

FIgURE 3: The difference grid layout of 13 nodes.

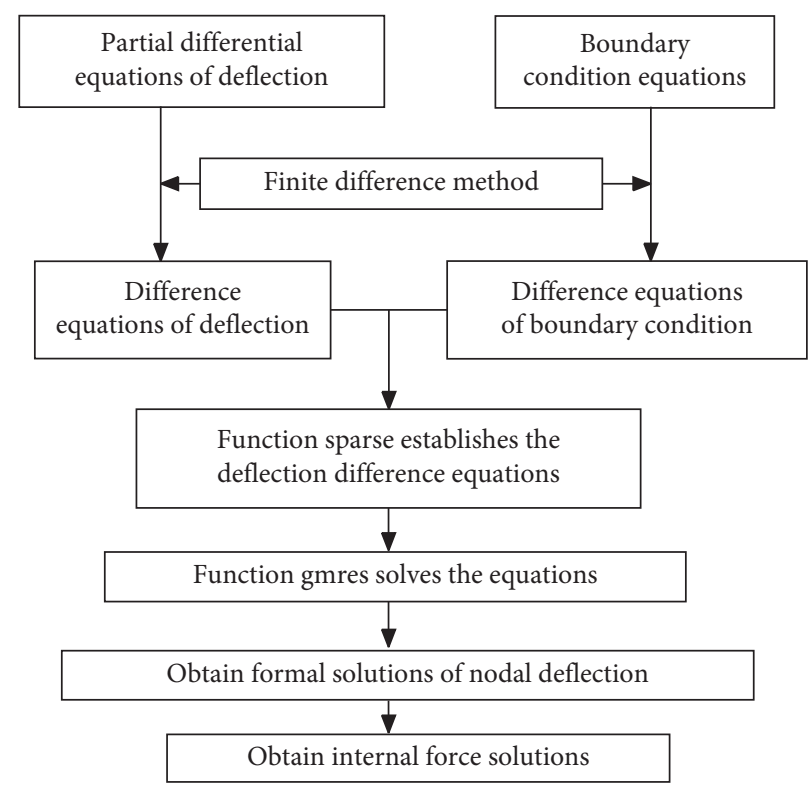

FIGURE 4: Process of solving partial differential equations. 


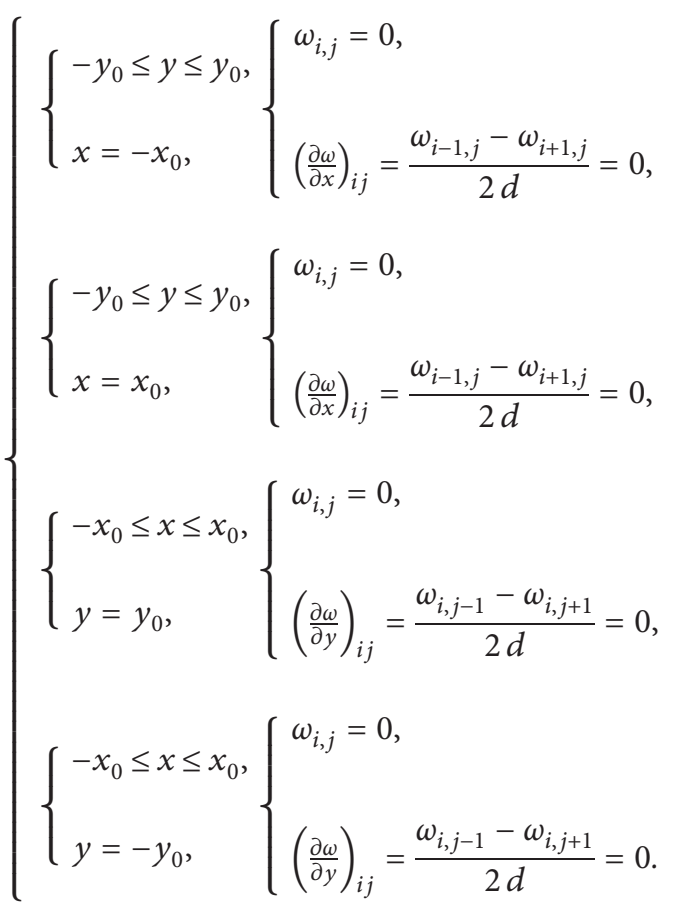

3.2. Calculation Process. According to the finite difference method, the 13-node difference equation should be established for any node whose deflection is unknown within the area of $S_{1}$ and the $S_{2}$ area of the main roof. The nodes whose deflection is unknown can then be obtained by constructing all nodal difference equations and the boundary condition equations.

Figure 4 presents the specific process of solving the partial differential equations. The process of solving partial differential equations needs to adopt the Sparse function in Matlab to form algebraic equations for a sparse matrix, and each nodal deflection solution can be obtained by using function Gmres [37] to solve the algebraic equations.

After solving each nodal deflection of the main roof, the nodal internal force solutions can be obtained by

$$
\left\{\begin{array}{l}
\left(M_{x}\right)_{i j}=-D\left(\frac{\partial^{2} \omega}{\partial x^{2}}+\mu \frac{\partial^{2} \omega}{\partial y^{2}}\right)_{i j} \\
=-\frac{D}{d^{2}}\left[\left(\omega_{i-1, j}-2 \omega_{i, j}+\omega_{i+1, j}\right)-\mu\left(\omega_{i, j-1}-2 \omega_{i, j}+\omega_{i, j+1}\right)\right] \\
\left(M_{y}\right)_{i j}=-D\left(\frac{\partial^{2} \omega}{\partial y^{2}}+\mu \frac{\partial^{2} \omega}{\partial x^{2}}\right)_{i j} \\
=-\frac{D}{d^{2}}\left[\left(\omega_{i, j-1}-2 \omega_{i, j}+\omega_{i, j+1}\right)-\mu\left(\omega_{i-1, j}-2 \omega_{i, j}+\omega_{i+1, j}\right)\right] \\
\left(M_{x y}\right)_{i j}=-D(1-\mu)\left(\frac{\partial^{2} \omega}{\partial x \partial y}\right)_{i j} \\
=-\frac{D(1-\mu)}{4 d^{2}}\left(\omega_{i-1, j-1}-\omega_{i+1,-1}+\omega_{i+1, j+1}-\omega_{i-1, j+1}\right)
\end{array}\right.
$$

where $\left(M_{x}\right)_{i j}$ is the nodal moment of the $x$-component; $\left(M_{y}\right)_{i j}$ is the nodal moment of the $y$-component; and $\left(M_{x y}\right)_{i j}$ is the nodal twisting moment.

\section{Example and Analysis}

The thin plate model on an elastic foundation with an elastic foundation boundary in backfill mining was investigated under realistic geological conditions. Variations of the internal force and deflection of the main roof with $E, h, \mu, k_{1}$ and $k_{2}$ were studied using the above equations for theoretical calculations.

The I26 working face of the Xingdong mine (length $\mathrm{AB}=70 \mathrm{~m}$ and advancing length $\mathrm{AD}=200 \mathrm{~m}$ in Figure 2) adopted the backfill bag of high-water material to backfill mining, with a backfill rate of $100 \%$. This working face was used to obtain realistic conditions for the calculations. Based on the above analysis, when $A_{1} B_{1}=A_{1} D_{1}=600 \mathrm{~m}$, the outer boundary can be regarded as fixed boundary.

In the I26 working face, the average angle of the coal seam was $4-6^{\circ}$, mining height was $4.5 \mathrm{~m}$, and the thickness of the main roof was $10 \mathrm{~m}$. Young's modulus of the main roof was $26 \mathrm{Gpa}$ and the elastic foundation coefficient $k_{1}$ was $1000 \mathrm{MN} / \mathrm{m}^{3}$. The key rock thickness, which overlies the main roof, was $110 \mathrm{~m}$ and the average unit weight of the rock was $0.024 \mathrm{MN} / \mathrm{m}^{3}$. Therefore, the load carried by the main roof was $q_{0}=2.64 \mathrm{Mpa}$. The elastic foundation coefficient $k_{2}$ of the high-water material used during the backfill mining process was $20 \mathrm{MN} / \mathrm{m}^{3}-220 \mathrm{MN} / \mathrm{m}^{3}$.

\subsection{Fracture Criterion.}

$$
M_{1}, M_{3}=\frac{M_{x}+M_{y}}{2} \pm \sqrt{\left(\frac{M_{x}-M_{y}}{2}\right)^{2}+\left(M_{x y}\right)^{2}},
$$

where $M_{1}$ is the maximum principal bending moment; $M_{3}$ is the minimum principal bending moment; $M_{x}$ is the moment of $x$-component; $M_{y}$ is the moment of $y$-component; and $M_{x y}$ is the nodal twisting moment.

$$
\begin{aligned}
& \left.\begin{array}{l}
\left(M_{1}\right)_{i j} \\
\left(M_{3}\right)_{i j}
\end{array}\right\}=\frac{\left(M_{x}\right)_{i j}+\left(M_{y}\right)_{i j}}{2} \\
& \pm \sqrt{\left(\frac{\left(M_{x}\right)_{i j}-\left(M_{y}\right)_{i j}}{2}\right)^{2}+\left(M_{x y}\right)_{i j}^{2}}
\end{aligned}
$$

where $\left(M_{1}\right)_{i j}$ is the nodal maximum principal moment; $\left(M_{3}\right)_{i j}$ is the nodal minimum principal moment.

Because the tensile strength of the rock is much less than the compressive strength, the principal moment of rock is compared with the ultimate bending moment of rock to judge whether the rock has failed or not. The maximum principal moment $M_{1}$ and minimum principal moment $M_{3}$ are obtained by equation (12), and the difference equation of equation (12) is equation (13). The moments $\left(M_{x}\right)_{i j},\left(M_{y}\right)_{i j}$ and $\left(M_{x y}\right)_{i j}$ in equation (13) can be obtained by equation (11). The extreme points of the principal moment are extracted from the cloud chart of the principal moment, which are shown in Figure 5. 


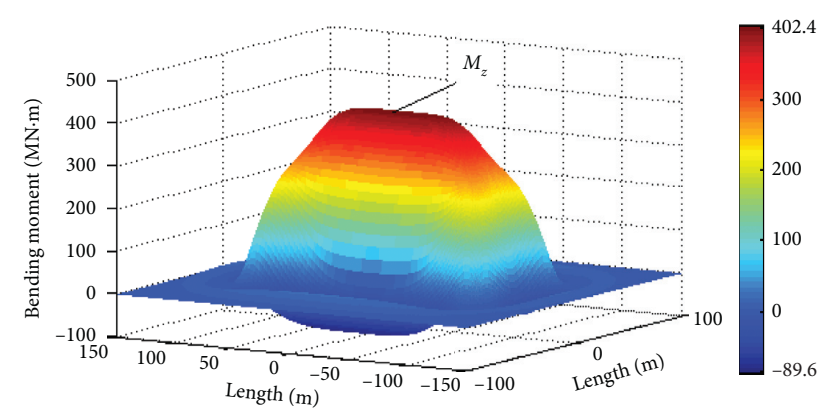

(a)

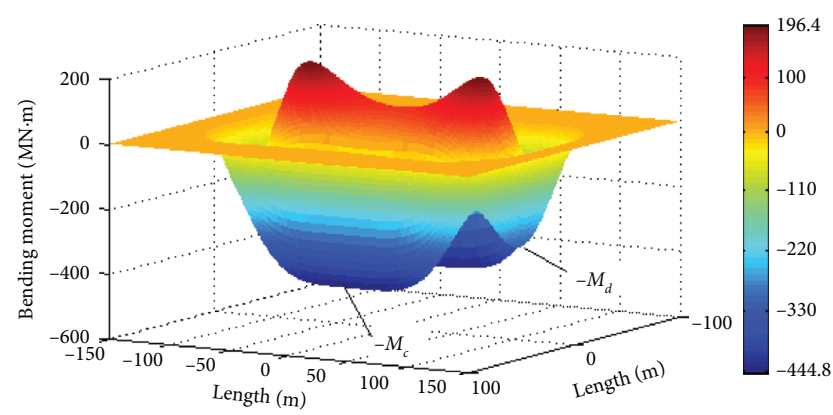

(c)

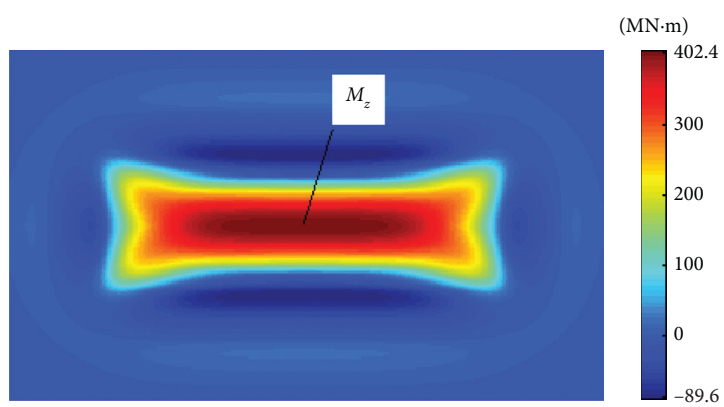

(b)

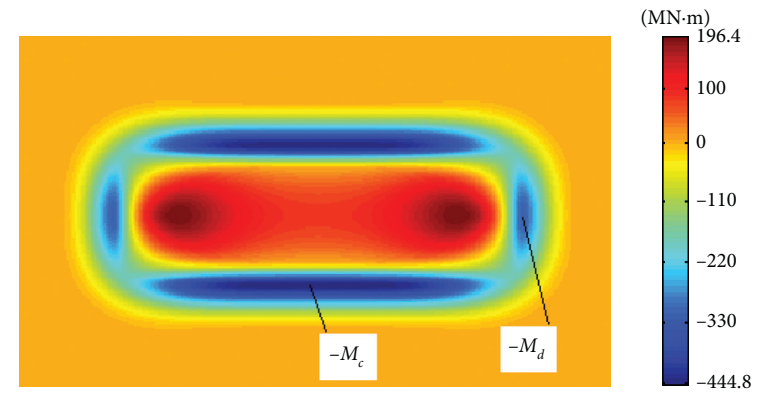

(d)

Figure 5: Principal moment feature when $k_{2}=20 \mathrm{MN} / \mathrm{m}^{3}$. (a) Three-dimensional cloud chart of principal moment $M_{1}$; (b) plane cloud chart of principal moment $M_{1}$; (c) cloud chart of principal moment $M_{3}$; (d) plane cloud chart of principal moment $M_{3}$.

\subsection{Effect of Elastic Foundation Coefficient $k_{2}$ of Backfill Body in Backfill Mining}

4.2.1. Basic Principles and Distribution Pattern of the Principal Moment. The elastic foundation coefficient of the backfill body is the key material factor to decide the backfill effect. Here, the backfill rate was $100 \%$. The elastic foundation coefficient $k_{2}$ was $\sim 20 \mathrm{MN} / \mathrm{m}^{3}-220 \mathrm{MN} / \mathrm{m}^{3}$. When $k_{2}=20 \mathrm{MN} / \mathrm{m}^{3}$ and $k_{2}=180 \mathrm{MN} / \mathrm{m}^{3}$, cloud charts of the principal moment in backfill mining were plotted, as shown in Figures 5 and 6.

From Figures 5 and 6, we can obtain the distribution of the principal moment during backfill mining: principal moments $M_{1}$ and $M_{3}$ in the middle area of the main roof directly overlying the backfill body were all positive bending moments; namely, the lower surface of the main roof bores the tensile stress and the upper surface of the main roof bores the compressive stress in this area. The nodal principal moments $M_{3}$ on the long side and short side area with a certain distance to the coal wall $\left(L_{\mathrm{c}}\right)$ were negative bending moments; namely, the upper surface of the main roof bores the tensile stress and the lower surface of main roof bores the compressive stress in this area.

According to the distribution characteristics of the principal moment in Figures 5 and 6, the coordinates of the extreme points of the main roofs principal moment were plotted, as shown in Figure 7.

When the value of $k_{2}$ was smaller $\left(k_{2}=20 \mathrm{MN} / \mathrm{m}^{3}\right)$, and according to the distribution characteristics of the principal moment in Figure 5, the coordinates of the extreme points of the principal moment were plotted, as shown in Figure 7(a).
The maximum absolute value of the principal moment of main roof in backfill area was at the midpoint with a coordinate of $(0,0)$, which was set to $M_{\mathrm{z}}$, and $M_{\mathrm{z}}=\left.M_{1}\right|_{(0,0)}$; the maximum absolute value of the principal moment on the long side area with a certain distance to the coal wall $\left(L_{\mathrm{c}}\right)$ was the negative value of the minimum principal moment $M_{3}$, which was set to $M_{\mathrm{c}}$, the coordinates of which were $\left(0, b+L_{\mathrm{c}}\right)$ and $\left(0,-b-L_{\mathrm{c}}\right)$. The distance of the $M_{\mathrm{c}}$ advancing coal wall was set to $L_{c}$, and $M_{c}=-\left.M_{3}\right|_{\left(0, b+L_{c}\right)}=-\left.M_{3}\right|_{\left(0,-b-L_{c}\right)}$; the maximum absolute value of the principal moment on the short side area with a certain distance to the coal wall $\left(L_{\mathrm{c}}\right)$ was the negative value of the minimum principal moment $M_{3}$, which was set to $M_{d}$, and the coordinates of $M_{d}$ are $\left(a+L_{d}, 0\right)$ and $\left(-a-L_{d}, 0\right)$. The distance of $M_{\mathrm{d}}$ advancing coal wall was set to $L_{\mathrm{d}}$, and $M_{d}=-\left.M_{3}\right|_{\left(a+L_{d}, 0\right)}=-\left.M_{3}\right|_{\left(-a-L_{d}, 0\right)}$.

The coordinates of the extreme points of the principal moment from Figure 6 were plotted when $k_{2}$ was larger $\left(k_{2}=180 \mathrm{MN} / \mathrm{m}^{3}\right)$, as shown in Figure $7(\mathrm{~b})$. The maximum principal moment of main roof in backfill area was set to $M_{\mathrm{zc}}$ whose coordinates were $\left(-a+L_{\mathrm{dc}}, b-L_{\mathrm{cc}}\right)$ and because of the symmetry, there were four points whose moments were all taken as $M_{z c}\left(\left.M_{z c}\right|_{\left(-a+L_{d c}, b-L_{c c}\right)}>M_{z}=\left.M_{1}\right|_{(0,0)}\right)$. In Figure $7(\mathrm{~b})$, the maximum absolute value of the principal moment of the long side area with a certain distance to the coal wall $\left(L_{\mathrm{c}}\right)$ was set to $M_{\mathrm{c}}$, and $M_{c}=-\left.M_{3}\right|_{\left(0, b+L_{c}\right)}=-\left.M_{3}\right|_{\left(0,-b-L_{c}\right)}$; the maximum absolute value of the principal moment of the short side area with a certain distance to the coal wall $\left(L_{\mathrm{c}}\right)$ wall was set to $M_{d}$ $\left(M_{d}=-\left.M_{3}\right|_{\left(a+L_{d}, 0\right)}=-\left.M_{3}\right|_{\left(-b-L_{c}, 0\right)}\right)$.

As shown in Figures 5 and 6 , when the value of $k_{2}$ became large $\left(k_{2}=180 \mathrm{MN} / \mathrm{m}^{3}\right)$, the maximum principal 


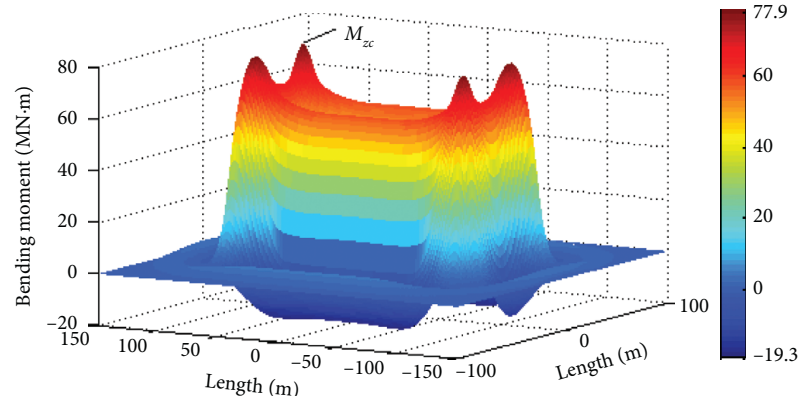

(a)

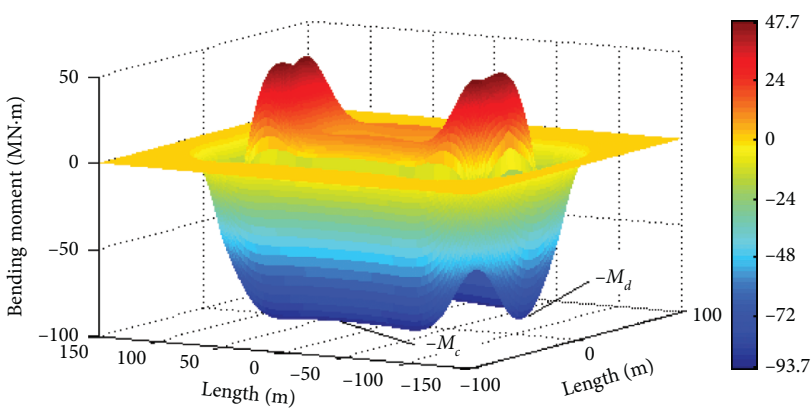

(c)

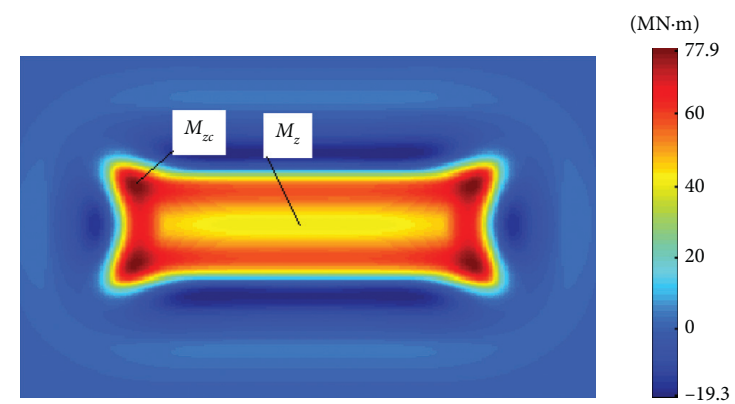

(b)

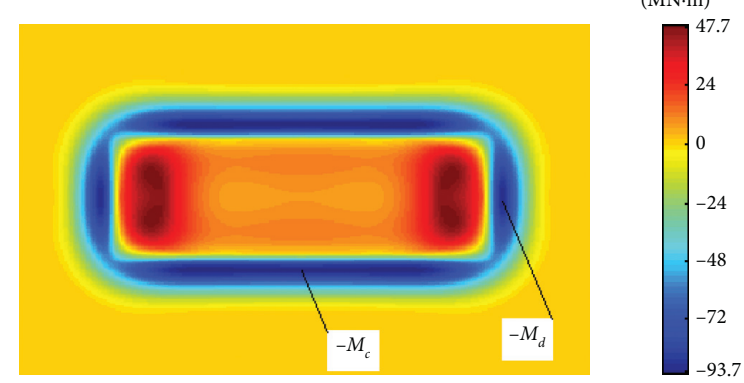

(d)

Figure 6: Principal moment feature when $k_{2}=180 \mathrm{MN} / \mathrm{m}^{3}$. (a) Three-dimensional cloud chart of principal moment $M_{1}$; (b) plane cloud chart of principal moment $M_{1}$; (c) three-dimensional cloud chart of principal moment $M_{3}$; (d) plane cloud chart of principal moment $M_{3}$.

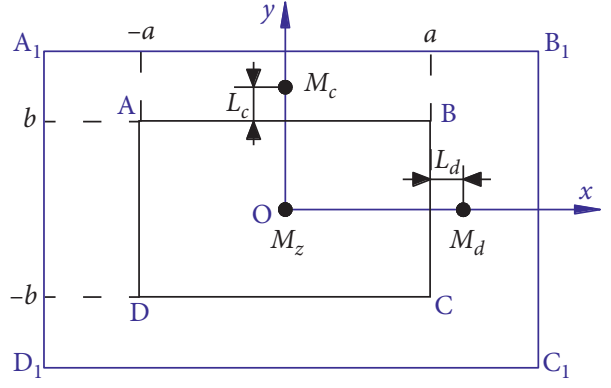

(a)

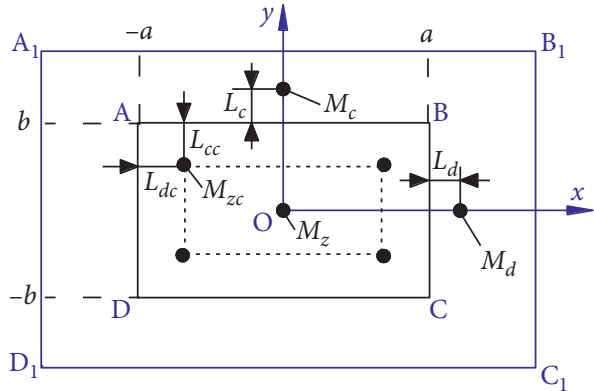

(b)

Figure 7: The coordinate of the extreme points of the main roof principal moment during backfill mining: (a) $k_{2}=20 \mathrm{MN} / \mathrm{m}^{3}$; (b) $k_{2}=180 \mathrm{MN} / \mathrm{m}^{3}$.

moment $M_{z}$ in the midpoint of the main roof transferred to the surrounding area and the points of the maximum principal moment were in the four corners of the study area. The maximum absolute value of the principal moment of main roof in the backfill area is denoted as $M_{\mathrm{zz}}$, and $M_{\mathrm{zz}}$ meets the following relationship: $M_{z z}=\max$ $\left\{\left.M_{1}\right|_{(0,0)},\left.M_{z c}\right|_{\left(-a+L_{d c}, b-L_{c c}\right)}\right\}$

Based on the above analysis, there appear to be three types of extreme points of the principal moments: the maximum absolute value of the principal moment $M_{\mathrm{zz}}$ of the main roof in backfill area, the maximum absolute value of the principal moment $M_{c}$ in the long side area, and the maximum absolute value of the principal moment $M_{d}$ in the short side area. Based on the above analysis and rock tensile properties, the lower surface of the middle area of main roof and the upper surface of long side and short side areas in front of the coal wall are the most susceptible to fracturing. Using the plate model on an elastic foundation with an elastic foundation boundary during backfill mining, the principles governing the fracturing of main roof are determined by the values of $M_{c}, M_{\mathrm{zz}}$ and $M_{d}$. The main roof can only fracture when the principal moment is larger than $M_{s}$ (the ultimate bending moment of the main roof). 
During backfill mining, the principal moments and the maximum subsidence $\omega_{0}$ of the main roof are related to $k_{2}$, $k_{1}, h, E$ and $\mu$. The principal movements and $L_{c}$ were then calculated with variations in the above mentioned variables and analyzed in order to study the variations in the maximum subsidence of the main roof.

4.2.2. Effects of the Elastic Foundation Coefficient $k_{2}$ of the Backfill Body. The following calculation examines the effect of the elastic foundation coefficient $k_{2}$ on the principal bending moment and maximum subsidence $\omega_{0}$ of the main roof.

(1) The variation of the principal bending moment of the main roof and $L_{\mathrm{c}}$ with the elastic foundation coefficient $k_{2}$ of the backfill body

Figure 8 shows the variations of the principal bending moments of the main roof and $L_{c}$ with the elastic foundation coefficient $k_{2}$ of the backfill body. The backfill body significantly reduced the value of the maximum principal bending moment of the main roof and improved the stability of the main roof. The principal bending moments $\left(M_{c}, M_{d}\right.$ and $M_{z z}$ ) continuously decreased with the increase in values of $k_{2}$. The value of the principal bending moment $M_{\mathrm{zz}}$ was highly sensitive to $k_{2}$, and comparatively the principal bending moment $M_{d}$ was less sensitive. The principal bending moments $M_{c}$ and $M_{d}$ were finally almost equal with an increase in $k_{2}$. In this situation, the long side and short side of the main roof almost fractured simultaneously when the maximum principal bending moment of the main roof increased to the ultimate bending moment $M_{s}$. There should be very little decrease in the principal bending moments when $k_{2}$ increases to some extent. The initial fracture position of the main roof was in the long side area, which is located in front of the coal wall with a $M_{c}$ value greater than $M_{s}$. $L_{c}$ continuously increased with the increase in $k_{2}$. Specifically, when $M_{c}$ was greater than $M_{s}$, the larger the values of $k_{2}$, the further the distance between the fracture line of main roof and the coal wall (refer to Figure 8).

(2) Variation of the maximum subsidence $\omega_{0}$ of the main roof with an elastic foundation coefficient $k_{2}$ of the backfill body

Figure 9 shows the variation of the maximum subsidence $\omega_{0}$ of the main roof with an elastic foundation coefficient $k_{2}$ of the backfill body. The maximum subsidence $\omega_{0}$ of the main roof appeared to decrease with the increase in $k_{2}$. The maximum subsidence should decrease very little when $k_{2}$ increases to some extent.

Using the above calculations and formulas, further study should be conducted to further describe the principal bending moments and the maximum subsidence $\omega_{0}$ of main roof with an elastic foundation coefficient $k_{1}$ by varying the coal seam,

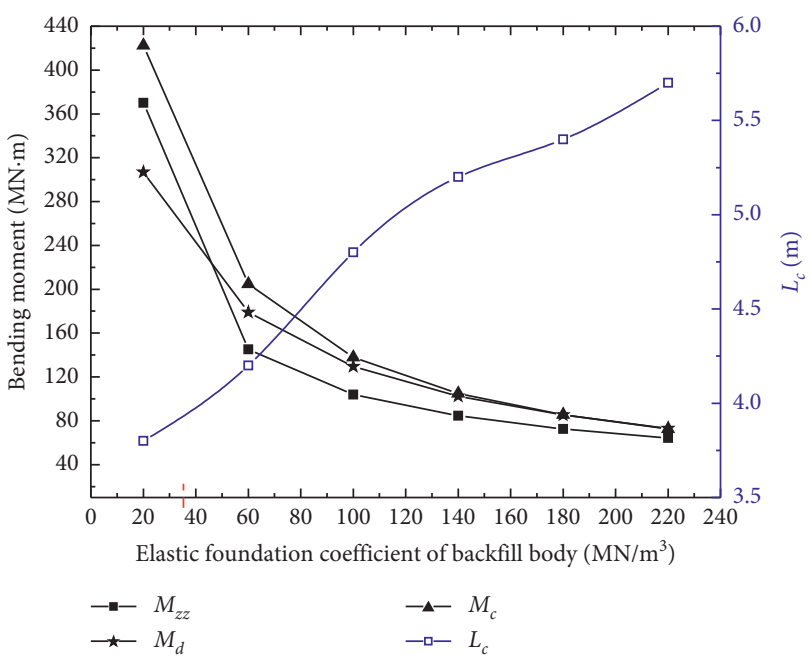

FIGURE 8: Change in the principal bending moments and $L_{c}$ with elastic foundation coefficient $k_{2}$ of backfill body.

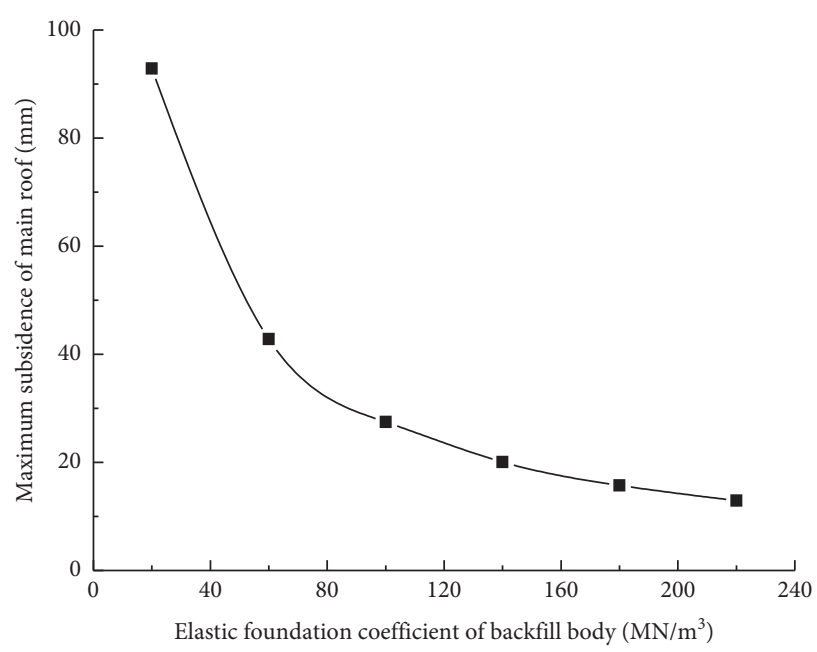

FIgURE 9: Change in the maximum subsidence $\omega_{0}$ of the main roof with variable $k_{2}$.

thickness $h$ of the main roof, Young's modulus $E$ of the main roof, and Poisson's ratio $\mu$ of the main roof, in order to better and widely study fracture principles and subsidence of the main roof during backfill mining.

4.3. Effect of the Elastic Foundation Coefficient $k_{1}$ of the Coal Seam in Backfill Mining. The elastic foundation coefficient $k_{1}$ of the coal seam mainly reflects the limitation of the displacement of the main roof. We then analyzed variations of the principal bending moments and the maximum subsidence $\omega_{0}$ with an elastic foundation coefficient $k_{1}$.

(1) Variations in the principal bending moments and $L_{c}$ with $k_{1}$.

Variations in the principal bending moments of the main roof and the distance to the coal wall $L_{c}$ with an elastic foundation coefficient $k_{1}$ are presented in 
Figure 10. The principal bending moments $\left(M_{c}, M_{d}\right.$ and $M_{z z}$ ) apparently increased with the increase in $k_{1}$, and comparatively the principal bending moment $M_{z z}$ had a smaller growth rate. When the principal moment $M_{\mathrm{c}}$ was greater than the ultimate moment $M_{\mathrm{s}}$, the larger the value of $k_{1}$ (the harder the coal seam), the closer the distance between the fracture line of the main roof and the coal wall (refer to Figure 10). Therefore, the influence of the boundary condition on the principal bending moment of main roof and $L_{c}$ cannot be neglected. In other words, the influence of the boundary condition on the fracture position of main roof cannot be neglected.

(2) Variations in the maximum subsidence $\omega_{0}$ of the main roof with an elastic foundation coefficient $k_{1}$ of coal seam.

The change in the maximum subsidence $\omega_{0}$ with an elastic foundation coefficient $k_{1}$ of the coal seam is presented in Figure 11. The maximum subsidence continuously decreased with an increase in $k_{1}$, whereas the sensitivity of the maximum subsidence $\omega_{0}$ decreased with an increase in $k_{1}$. The value of the maximum subsidence was reduced by approximately $10 \%$ with an increase in $k_{1}$ (varying from 1000 to $\left.8000 \mathrm{MN} / \mathrm{m}^{3}\right)$.

4.4. Effect of the Thickness h of the Main Roof. The thickness of the main roof can vary from mine to mine, depending on various circumstances (geology, previous mining, etc.). The effects of various thicknesses $h$ were analyzed on the maximum subsidence $\omega_{0}$ and the principal bending moments in order to encompass a wide range of scenarios.

(1) Change in the principal bending moments and $L_{c}$ with $h$

Figure 12 graphically presents the variations of each of the three principal bending moments and $L_{c}$ with various thicknesses of the main roof $h(4-12 \mathrm{~m})$. The principal bending moments $\left(M_{c}, M_{d}\right.$ and $\left.M_{z z}\right)$ continuously increased with the increase in the roof thickness. Principal bending moment $M_{\mathrm{zz}}$ was highly sensitive to $h$, and comparatively the principal bending moment $M_{d}$ was less sensitive. The principal bending moments $M_{c}$ and $M_{d}$ were almost equal when the thickness was relatively small $(4-8 \mathrm{~m})$. In such situation, the long side and short side area of the main roof almost fractured concurrently when the maximum principal bending moment of main roof increased to the ultimate bending moment $M_{s}$. $L_{c}$ increased linearly with the increase in the roof thickness. Actually, the thicker the roof, the further the distance between the fracture line of main roof and the coal wall (refer to Figure 12).

(2) Changes in the maximum subsidence of the main roof with various thicknesses $h$

Figure 13 shows the change in the maximum subsidence $\omega_{0}$ of the main roof with various thicknesses

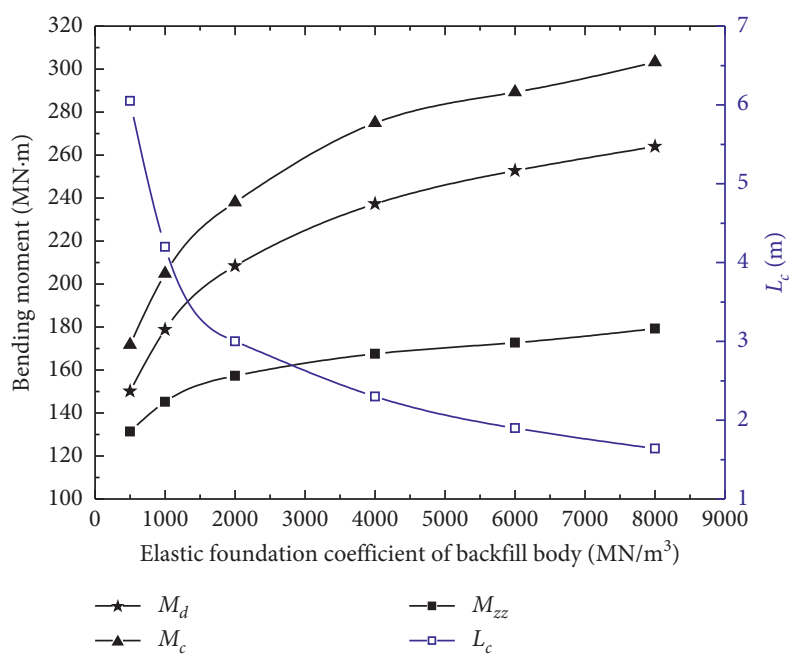

FIGURE 10: Change in the principal bending moments and $L_{c}$ with $k_{1}$.

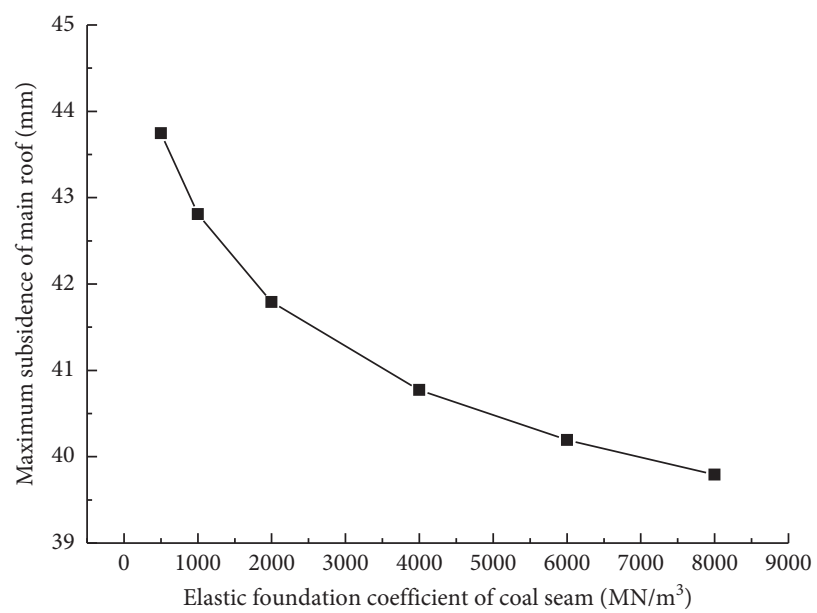

Figure 11: Change in the maximum subsidence $\omega_{0}$ with $k_{1}$

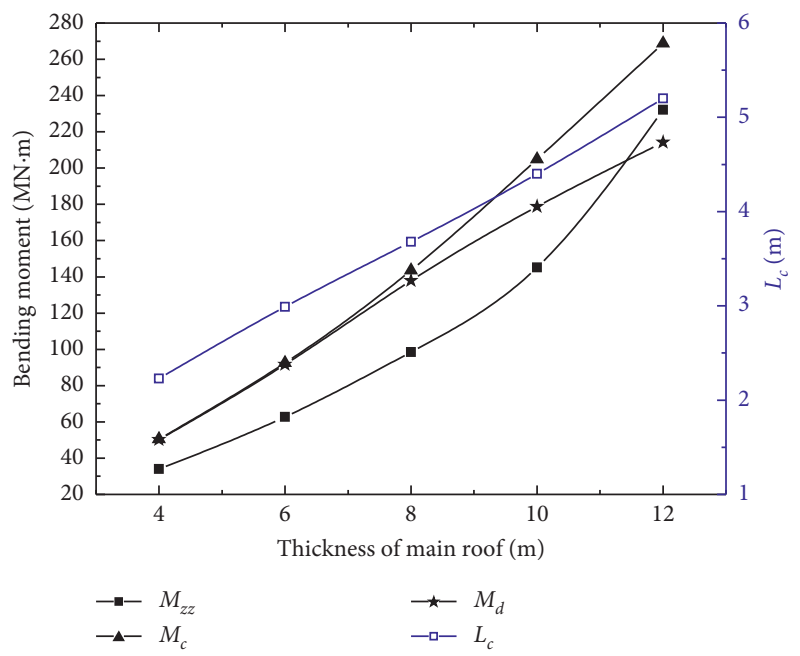

FIGURE 12: Change in the principal bending moments and $L_{c}$ with $h$. 


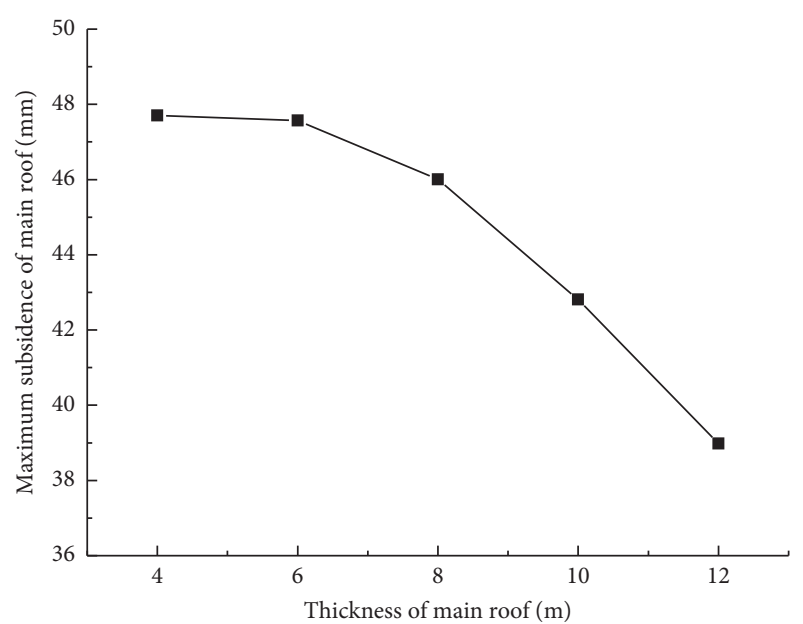

Figure 13: The maximum subsidence $\omega_{0}$ of main roof with roof thickness $h$.

(4-12 m). The maximum subsidence of the main roof continuously decreased with an increase in roof thickness, and the sensitivity of the maximum subsidence increased with an increase in the roof thickness.

4.5. Variations of Young's Modulus E of the Main Roof in Backfill Mining. Young's modulus $E$ of the main roof was then varied to analyze the effects on the principal bending moment and maximum subsidence $\omega_{0}$.

(1) Changes in the principal bending moments and $L_{c}$ with various $E$

Figure 14 shows the changes in the principal bending moments and $L_{\mathrm{c}}$ with various Young's modulus values $E(10-75 \mathrm{GPa})$. The principal bending moments $M_{c}$ and $M_{d}$ were almost equal when $E$ was relatively small $(10 \mathrm{GPa})$. In this condition, the long side and short side area of the main roof almost fractured concurrently when the maximum principal bending moment of the main roof increased to $M_{s}$. When the value of Young's modulus reached $70 \mathrm{GPa}$, $M_{c}$ and $M_{z z}$ were nearly equal. In such situation, the long side and the middle area of the main roof almost fractured simultaneously when the principal bending moment was greater than $M_{s}$. The larger the $E$, the farther the $L_{c}$, and the farther the distance between the fracture line of main roof and the coal wall (refer to Figure 14). Based on the effect of Young's modulus on the main bending moment, we can conclude that the greater Young's modulus $E$ value and the tensile strength must also be large within the main roof to ensure the main roof does not fracture.

(2) Change in maximum subsidence $\omega_{0}$ with various Young's modulus $E$ values of the main roof

Figure 15 shows the change in the maximum subsidence $\omega_{0}$ with an increase in Young's modulus $E$ of the main roof. Maximum subsidence of the

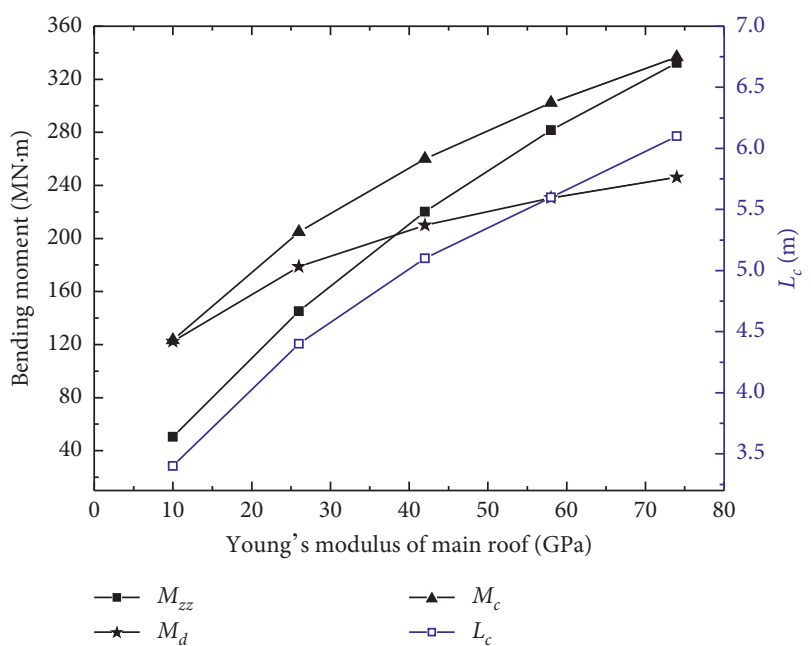

FIGURE 14: Change in the principal bending moments and $L_{c}$ with $E$.

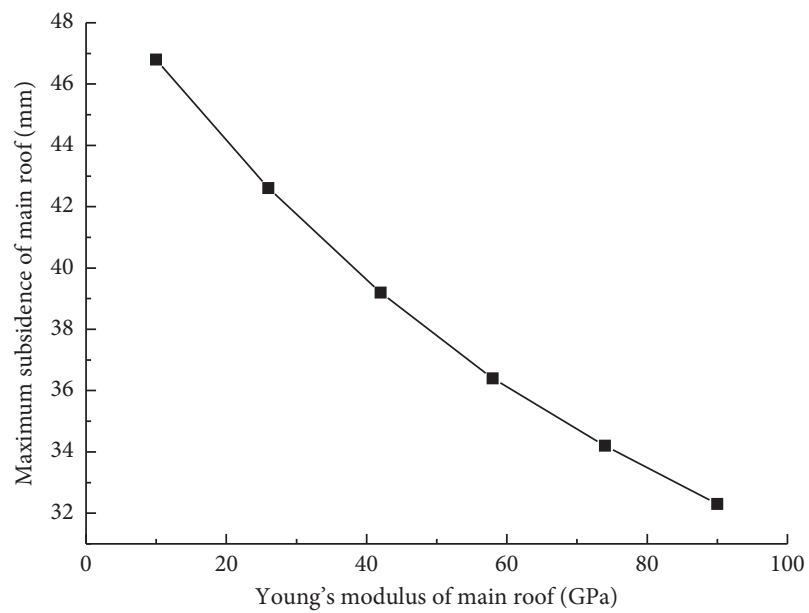

Figure 15: The change in the maximum subsidence $\omega_{0}$ with various $E$.

main roof continuously decreased with an increase in $E$, and the sensitivity of $\omega_{0}$ decreased with an increase in $E$.

4.6. Effects of Poisson's Ratio $\mu$ on the Main Roof in Backfill Mining. Variations of the principal moments and maximum subsidence $\omega_{0}$ with Poisson's ratio $\mu$ of main roof are discussed in the following calculations. Generally, the value of Poisson's ratio varies from 0.1 to 0.3 .

(1) Changes in the principal moments and $L_{c}$ with various Poisson's ratio $\mu$ values

Figure 16 shows variations in principal moments and $L_{c}$ with changes in Poisson's ratio $\mu(0.10-0.30)$. The principal moments $\left(M_{c}, M_{d}\right.$ and $\left.M_{\mathrm{zz}}\right)$ gradually increased with the increase in $\mu$, and $L_{c}$ remained almost unchanged. Poisson's ratio $\mu$ had little effect on principal moments and $L_{c}$; therefore, Poisson's ratio 


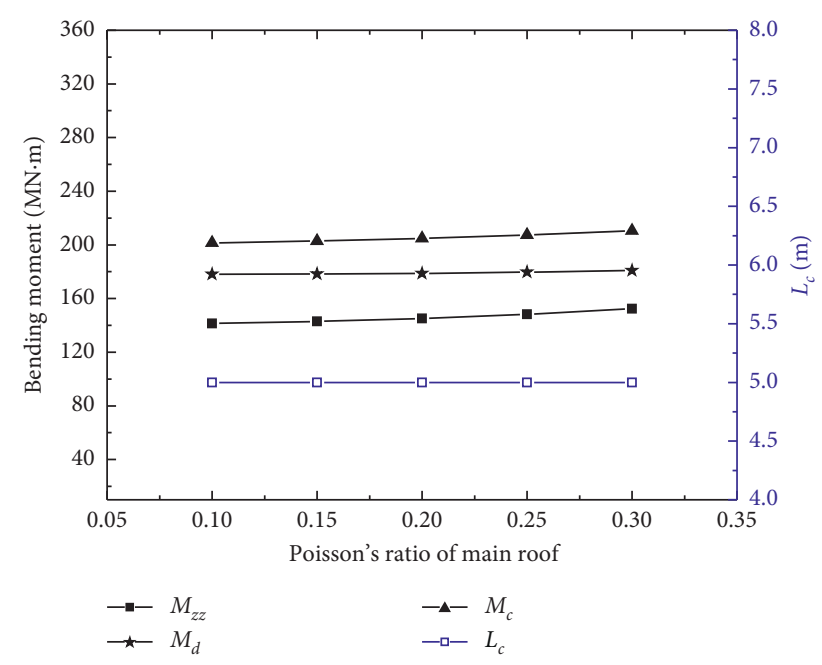

FIGURE 16: The variation of principal bending moments and $L_{c}$ with $\mu$.

would have little effect on the position of fracturing in the main roof.

(2) Variations of maximum subsidence $\omega_{0}$ of the main roof with $\mu$

Figure 17 shows how the maximum subsidence $\omega_{0}$ of the main roof varies with $\mu(0.10-0.30)$. The maximum subsidence slowly decreased with an increase in Poisson's ratio. The maximum subsidence values $\omega_{0}$ when $\mu=0.1$ and $\mu=0.3$ were almost equal. Overall, Poisson's ratio has little effect on the maximum subsidence of the main roof.

4.7. Effects of $k_{1}, k_{2}$, Ein Backfill Mining. As observed through the above calculations, both the distribution of the principal bending moments of the main roof and the distance of the advancing coal seam $L_{c}$ were influenced by $k_{1}, k_{2}$ and $E$. The value of the principal bending moments decreased as $k_{2}$ increased while the principal bending moments increased as $k_{1}$ increased; $L_{c}$ decreased as $k_{1}$ increased while $L_{c}$ increased as $k_{2}$ increased; the principal bending moments and $L_{c}$ increased as $E$ increased. These calculations only analyzed the variations of the principal bending moments with a single parameter. To better characterize backfill mining, multiple parameters were analyzed to determine the effects of the principal bending moments of the main roof and $L_{c}$.

(1) Variations of the principal moments and $L_{c}$ with $k_{1}$, $k_{2}, E$

Figure 18 shows the variations of the principal bending moments and $L_{c}$ with $k_{1}, k_{2}$, and $E$ all taken into consideration. The bending moments of the main roof and $L_{c}$ did not change when $k_{1}, k_{2}$ and $E$ changed but the ratio of the three $\left(k_{1} / k_{2} / E\right)$ remained constant, and the fracture position was unchanged.

(2) Changes in the maximum subsidence $\omega_{0}$ with various $k_{1}, k_{2}, E$

Figure 19 shows the changes in the maximum subsidence $\omega_{0}$ with various $k_{1}, k_{2}$ and $E$. The

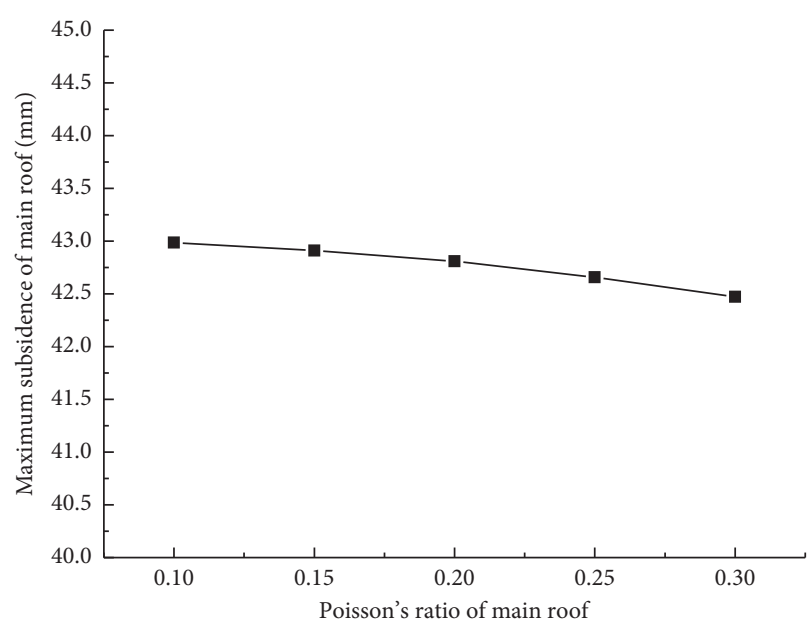

Figure 17: Variations of the maximum subsidence $\omega_{0}$ with $\mu$.

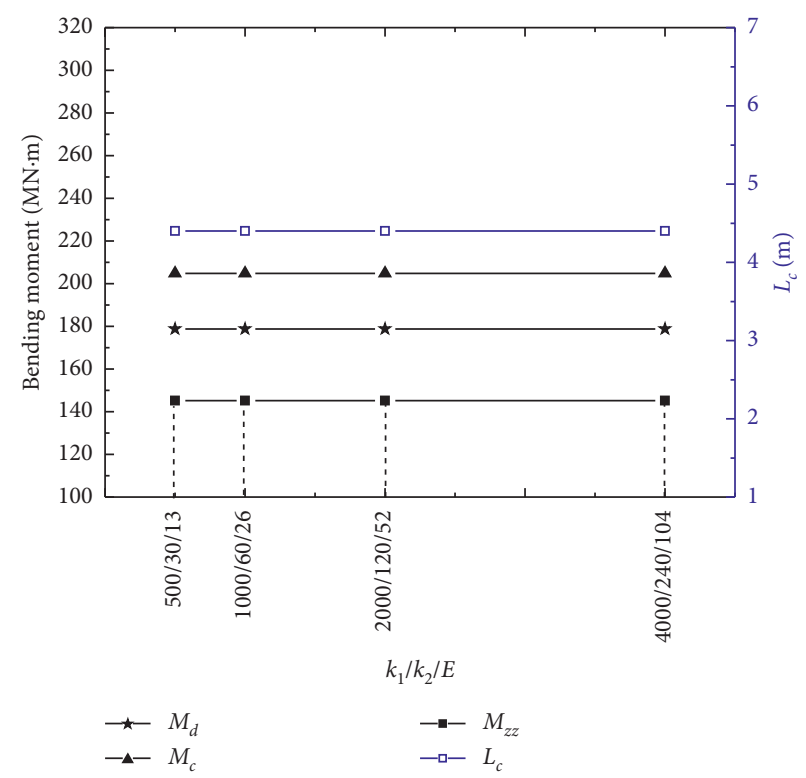

FIGURE 18: Variation of the principal bending moments with $k_{1} / k_{2} / E$.

maximum subsidence $\omega_{0}$ of the main roof decreased gradually and the reduction extent significantly decreased when $k_{1}, k_{2}$ and $E$ increased but with a constant ratio $\left(k_{1} / k_{2} / E\right)$. The principal moments and fracture position of the main roof remained constant with the constant ratio $\left(k_{1} / k_{2} /\right.$ $E)$, although the maximum subsidence $\omega_{0}$ changed significantly.

4.8. Comparison of Model Conclusions. Under the condition of backfill mining, the mechanical model of thin plate was the most suitable to study the actual characteristics of overburden movement, while the rock beam model could only study the local mechanical characteristics in the mining area. Therefore, the model in this paper mainly studied the mechanical model of plate structure under the condition of 


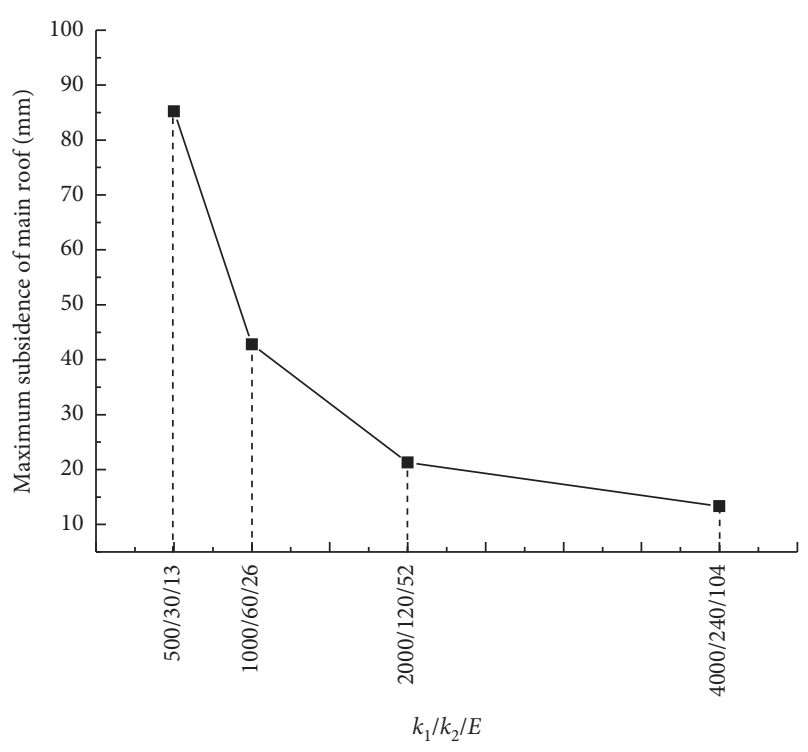

FIGURE 19: Variation of the maximum subsidence $\omega_{0}$ with various $k_{1}, k_{2}$ and $E$.

backfill rather than the mechanical model of rock beam with defects.

In general, the thin plate mechanical model with fixed support boundary around the overburden in the backfill area was widely used [31], so the comparison object selected in this paper was the thin plate mechanical model with fixed support boundary of four sides.

The main differences were as follows:

(1) The elastic foundation coefficient $k_{2}$ of backfill body, the elastic foundation coefficient $k_{1}$ of the coal seam, the thickness $h$, and Young's modulus $E$ of main roof could affect the values and positions of the main roof principal moments, the distance of principal moments advancing coal wall. However, the traditional thin plate model with fixed support boundary could not get these useful conclusions.

(2) In this paper, it was found that the fracture location of the main roof was deep into the coal body area, while the traditional model showed that the first fracture location of the main roof was on the long side of the mining area and along the coal wall, which was independent of the boundary conditions, backfill body parameters, thickness, and Young's modulus of the main roof.

(3) In particular, the weight relationship of the influencing factors of main roof fracture law was obtained; that is, when the ratio $\left(k_{1} / k_{2} / E\right)$ was constant, the magnitude of the principal bending moments was constant, but the maximum subsidence changed significantly, which could not be obtained by the traditional plate structure model with fixed boundary.

It could be seen that the conclusion of the traditional model had great limitations. The model and the conclusions of this paper were more practical and helpful to guide the engineering practice, which effectively made up for the shortcomings of the traditional model.

\section{Engineering Practice}

Changes in the principal moments of the main roof, the distance of the $M_{c}$ advancing coal wall $L_{c}$, and the maximum subsidence $\omega_{0}$ with $k_{1}, k_{2}, E, h, \mu$ and the ratio of $k_{1} / k_{2} / E$ in backfill mining were examined to assist with forming the basis for engineering practice. To verify the theoretical calculations, the value of the elastic foundation coefficient $k_{2}$ in the I26 backfill working face of Xingdong mine was determined. Subsidence of main roof and support pressure were then measured during mining.

(1) Calculating the elastic foundation coefficient of the backfill body

The tensile strength of the main roof was measured at $12.5 \mathrm{MPa}$ and the ultimate bending moment of the main roof was $208 \mathrm{MN} \mathrm{m}$ in the I26 backfill working face. When the elastic foundation coefficient of the backfill body was $k_{2}=60 \mathrm{MN} / \mathrm{m}^{3}$, the maximum principal moment of main roof was $M_{\mathrm{c}}=199 \mathrm{MN} /$ $\mathrm{m}^{3}$, and the distance of the $M_{c}$ advancing coal wall was $L_{c}=4 \mathrm{~m}$ (refer to Figure 8).

To control the ground deformation and protect the main roof from fracturing, the value of $k_{2}$ of the backfill body should be about $56-60 \mathrm{MN} / \mathrm{m}^{3}$, while, using previous methods [31], the thin plate mechanical model with fixed support boundary, to calculate $k_{2}$, the $k_{2}$ would be $290 \mathrm{MN} / \mathrm{m}^{3}$. Clearly, the result calculated by the previous method was much larger than that calculated by the present method. From Figure 9 we know that the maximum subsidence of main roof given by theoretical calculation should be $44.5 \mathrm{~mm}$ when the value of $k_{2}$ is $60 \mathrm{MN} /$ $\mathrm{m}^{3}$.

The I26 working face adopted the backfill bag of high-water material to backfill mining. In order to meet the production need of the working face and simultaneously ensure the convenience of backfilling the goaf, the size of the backfill bag was designed to be $15 \times 2.2 \times 4.8 \mathrm{~m} \quad$ (length $\times$ width $\times$ height). The high-water material used in the I 26 working face was a quick-setting high-water material. The material was prepared from the mixture of materials $A$ and $B$, which solidify after mixing for 10-20 minutes. The elastic foundation coefficient $k_{2}$ of the prepared highwater material was about $56-60 \mathrm{MN} / \mathrm{m}^{3}$.

(2) Field observation

The final main roof subsidence was about $48 \mathrm{~mm}$, which was consistent with the value of theoretical calculations presented here.

Mine pressure monitoring results showed that there was no periodic weighting during the mining of the I26 working face, which indicates that the main roof did not periodically fracture, and the borehole observation also indicated that the main roof did not 
fracture. Overall, it is feasible to determine the elastic foundation coefficient $k_{2}$ of the backfilling material using the proposed theoretical calculation. The result calculated by the previous method was much larger than that calculated by the present method. Trying to achieve the larger elastic foundation coefficient of the backfilling material is much more costly and excessive for the given situation. Thus, the thin plate model on the elastic foundation with an elastic foundation boundary based on the actual boundary of the surrounding rock can better guide practice and can bring better economic benefits.

\section{Conclusions}

It is very important to establish a mechanical model that is in line with the actual characteristics of the project to effectively analyze and solve the mining engineering problems.

In this paper, the thin plate model with elastic foundation boundary of overlying strata for backfill mining was established, and the calculation method was given. The results showed that the calculation method was feasible. Through this model, the fracturing law of the main roof was studied in detail, and new conclusions that the traditional model could not get were obtained, which made up the defects of the traditional model.

(1) The elastic foundation coefficient $k_{1}$ of the coal seam, the elastic foundation coefficient $k_{2}$ of backfill body, the thickness $h$, Young's modulus $E$, and Poisson's ratio $\mu$ of main roof could affect the values and positions of the main roof principal moments, the distance of principal moments advancing coal wall, and the maximum subsidence $\omega_{0}$; the influence of $k_{2}$ on the principal moments and maximum subsidence $\omega_{0}$ of the main roof was the largest, while the influence of $\mu$ was the smallest; the values and positions of each of the principal moments remained unchanged but $\omega_{0}$ decreased significantly when $k_{1}, k_{2}$ and $E$ increased and maintained the constant ratio $\left(k_{1} / k_{2} / E\right)$.

(2) According to the variations in the principal moment, there were three types of initial fracturing of the main roof: fracturing in the long side ahead of the coal wall, fracturing in the long side ahead of the coal wall and the middle area of the main roof simultaneously, and fracturing in the long side ahead of the coal wall and short side ahead of the coal wall simultaneously, which was helpful to effectively monitor the fracturing position of the main roof in engineering practice.

(3) The elastic foundation coefficient $k_{2}$ of the backfill body calculated by the thin plate model on the elastic foundation with elastic foundation boundary was far less than the value of $k_{2}$ calculated by the thin plate model on an elastic foundation with fixed boundary. Using the I26 working face as verification of the calculation method, when the value of $k_{2}$ was $56-60 \mathrm{MN} / \mathrm{m}^{3}$, the main roof did not undergo periodic weighting during mining. It provided a new and more reliable calculation method for determining the elastic foundation coefficient of the backfill body in order to protect the main roof from fracturing.

(4) The calculation model in this paper effectively made up for the defects and deficiencies of the traditional mechanical model, especially in the fracturing law of the main roof, fracturing conditions, and the weight relationship of the influencing factors. The conclusions promote the theoretical progress and had important reference significance for engineering practice.

\section{Data Availability}

All data contained in this study are available upon request from the corresponding author.

\section{Conflicts of Interest}

The authors declare no conflicts of interest.

\section{Acknowledgments}

This research was funded by the China Postdoctoral Science Foundation (Grant no. 2019M650895), the National Natural Science Foundation of China (Grant no. 51974317), the National Natural Science Foundation of China (Grant no. 51504259), the Fundamental Research Funds for the Central Universities (Grant no. 2010QZ06), and the Yue Qi Young Scholar Project, China University of Mining and Technology, Beijing (Grant no. 800015Z1104).

\section{References}

[1] M. G. Qian, J. L. Xu, and X. X. Miao, "Green technique in coal mining," Journal of China University of Mining \& Technology, vol. 32, no. 4, pp. 343-348, 2003.

[2] Q. Y. Wu, J. W. Pang, S. Z. Qi et al., "Impacts of coal mining subsidence on the surface landscape in Longkou city," Environmental Earth Sciences, vol. 59, no. 4, pp. 783-791, 2009.

[3] Y.-B. Jung, W.-K. Song, D.-S. Cheon, D.-K. Lee, and J.-Y. Park, "Simple method for the identification of subsidence susceptibility above underground coal mines in Korea," Engineering Geology, vol. 178, pp. 121-131, 2014.

[4] T. Unlu, H. Akcin, and O. Yilmaz, "An integrated approach for the prediction of subsidence for coal mining basins," Engineering Geology, vol. 166, pp. 186-203, 2013.

[5] A. H. M. Ng, L. L. Ge, Y. G. Yan et al., "Mapping accumulated mine subsidence using small stack of SAR differential interferograms in the Southern coalfield of New South Wales, Australia," Engineering Geology, vol. 115, no. 1-2, pp. 1-15, 2010.

[6] M. G. Karfakis and E. Topuz, "Post mining subsidence abatements in Wyoming abandoned coal mines," Mining Science \& Technology, vol. 12, no. 3, pp. 233-240, 1991.

[7] J. Barbato, B. Hebblewhite, R. Mitra, and K. Mills, "Prediction of horizontal movement and strain at the surface due to longwall coal mining," International Journal of Rock Mechanics and Mining Sciences, vol. 84, pp. 105-118, 2016. 
[8] L. Li, K. Wu, and D.-W. Zhou, "AutoCAD-based prediction of 3D dynamic ground movement for underground coal mining," International Journal of Rock Mechanics and Mining Sciences, vol. 71, pp. 194-203, 2014.

[9] K.-S. Woo, E. Eberhardt, D. Elmo, and D. Stead, "Empirical investigation and characterization of surface subsidence related to block cave mining," International Journal of Rock Mechanics and Mining Sciences, vol. 61, pp. 31-42, 2013.

[10] J. Ju and J. Xu, "Surface stepped subsidence related to top-coal caving longwall mining of extremely thick coal seam under shallow cover," International Journal of Rock Mechanics and Mining Sciences, vol. 78, pp. 27-35, 2015.

[11] B. Yu, J. Zhao, T. Kuang, and X. Meng, "In situ investigations into overburden failures of a super-thick coal seam for longwall top coal caving," International Journal of Rock Mechanics and Mining Sciences, vol. 78, pp. 155-162, 2015.

[12] H.-J. Oh and S. Lee, "Integration of ground subsidence hazard maps of abandoned coal mines in Samcheok, Korea," International Journal of Coal Geology, vol. 86, no. 1, pp. 58-72, 2011.

[13] E. Can, Ş. Kuşcu, and C. Mekik, "Determination of underground mining induced displacements using GPS observations in Zonguldak-Kozlu Hard Coal Basin," International Journal of Coal Geology, vol. 89, no. 1, pp. 62-69, 2012.

[14] Ş. Düzgün, C. Künzer, and C. Ö. Karacan, "Applications of remote sensing and GIS for monitoring of coal fires, mine subsidence, environmental impacts of coal-mine closure and reclamation," International Journal of Coal Geology, vol. 86, no. 1, pp. 1-2, 2011.

[15] M. Li, J. Zhang, N. Zhou, and Y. Huang, "Effect of particle size on the energy evolution of crushed waste rock in coal mines," Rock Mechanics and Rock Engineering, vol. 50, no. 5, pp. 1347-1354, 2017.

[16] Q. Zhang, J.-x. Zhang, Y. Tai, K. Fang, and W. Yin, "Horizontal roof gap of backfill hydraulic support," Journal of Central South University, vol. 22, no. 9, pp. 3544-3555, 2015.

[17] Q. Zhang, J. Zhang, Y. Huang, and F. Ju, "Backfilling technology and strata behaviors in fully mechanized coal mining working face," International Journal of Mining Science and Technology, vol. 22, no. 2, pp. 151-157, 2012.

[18] Q. Zhang, J. X. Zhang, T. Kang, Q. Sun, and W. K. Li, "Mining pressure monitoring and analysis in fully mechanized backfilling coal mining face-a case study in Zhai Zhen coal mine," Journal of Central South University, vol. 22, no. 5, pp. 19651972, 2015.

[19] J. Zhang, B. Li, N. Zhou, and Q. Zhang, "Application of solid backfilling to reduce hard-roof caving and longwall coal face burst potential," International Journal of Rock Mechanics and Mining Sciences, vol. 88, pp. 197-205, 2016.

[20] J. Li, J. Zhang, Y. Huang, Q. Zhang, and J. Xu, "An investigation of surface deformation after fully mechanized, solid back fill mining," International Journal of Mining Science and Technology, vol. 22, no. 4, pp. 453-457, 2012.

[21] M. Benzaazoua, M. Fall, and T. Belem, "A contribution to understanding the hardening process of cemented pastefill," Minerals Engineering, vol. 17, no. 2, pp. 141-152, 2004.

[22] Z. D. Cui and H. H. Sun, "The preparation and properties of coal gangue based similar paste like backfill material," Journal of China Coal Society, vol. 35, no. 6, pp. 896-899, 2010.

[23] X. Qin, P. Wang, L. Liu, M. Wang, and J. Xin, "Sensitivity analysis of microstructure parameters and mechanical strength during consolidation of cemented paste backfill," Mathematical Problems in Engineering, vol. 2018, Article ID 5170721, 9 pages, 2018.
[24] H. Q. Zhou, C. J. Hou, X. K. Sun et al., "Solid waste paste filling for none-village-relocation coal mining," Journal of China University of Mining and Technology, vol. 35, no. 3, pp. 403-408, 2006.

[25] Y. Ding, G. M. Feng, and C. Z. Wang, "Experimental research on basic properties of super high-water packing material," Journal of China Coal Society, vol. 36, no. 7, pp. 1087-1092, 2011.

[26] Z. P. Yan, T. Y. Qi, L. K. Zhang, and C. J. Hou, "Study of ZKD quick setting materials with high water content and technique of pump packing," Journal of China Coal Society, vol. 22, no. 3, pp. 48-53, 1997.

[27] G. M. Feng, C. D. Sun, C. Z. Wang et al., "Research on goaf filling methods with super high-water material," Journal of China Coal Society, vol. 35, no. 12, pp. 1963-1968, 2010.

[28] J. X. Zhang, M. Li, Y. L. Huang et al., "Interaction between backfilling body and overburden strata in fully mechanized backfilling mining face," Disaster Advances, vol. 6, no. S5, pp. 1-7, 2013.

[29] X. X. Miao, Y. L. Huang, F. Ju et al., "Strata movement theory of dense backfill mining," Journal of China University of Mining and Technology, vol. 41, no. 6, pp. 863-867, 2012.

[30] J. Chen, J. P. Du, W. S. Zhang, and J. X. Zhang, "An elastic model of overlying strata movement during coal mining with gangue back-filling," Journal of China University of Mining and Technology, vol. 41, no. 1, pp. 14-19, 2012.

[31] M. Li, J. X. Zhang, H. Q. Jiang, Y. L. Huang et al., "A thin plate on elastic foundation model of overlying strata for dense solid backfill mining," Journal of China Coal Society, vol. 39, no. 12, pp. 2369-2373, 2014.

[32] Y. L. Huang, J. X. Zhang, B. F. An, and Q. Zhang, "Overlying strata movement law in fully mechanized coal mining and backfilling longwall face by similar physical simulation," Journal of Mining Science, vol. 47, no. 5, pp. 618-627, 2011.

[33] S. R. Xie, D. D. Chen, Y. D Sun, M. M. Gao, Y. J. Sun, and W. Shi, "Analysis on thin plate model of basic roof at elastic foundation boundary (I): first breaking," Journal of China Coal Society, vol. 41, no. 6, pp. 1360-1368, 2016.

[34] D. D. Chen, S. R. Xie, L. H. Fu, M. M. Gao, and H. Z. Song, "First fracture of the thin plate of main roof with three sides elastic foundation boundary and one side coal pillar," Journal of China Coal Society, vol. 42, no. 10, pp. 2528-2536, 2017.

[35] Z. Wang, X. Liang, and G. Liu, "An analytical method for evaluating the dynamic response of plates subjected to underwater shock employing mindlin plate theory and laplace transforms," Mathematical Problems in Engineering, vol. 2013, pp. 1-11, 2013.

[36] I. Park, T. Kim, and U. Lee, "Frequency domain spectral element model for the vibration analysis of a thin plate with arbitrary boundary conditions," Mathematical Problems in Engineering, vol. 2016, pp. 1-20, 2016.

[37] D. D. Chen, L. H. Fu, S. R. Xie, and J. C. Zeng, "Time-space relationship between periodic fracture of plate structure of main roof and rebound in whole region with elastic foundation boundary," Chinese Journal of Rock Mechanics and Engineering, vol. 38, no. 6, pp. 1172-1187, 2019.

[38] D. D. Chen, S. R. Xie, L. H. Fu, J. C. Zeng, F. X. Xie, and Q. Cheng, "First fracturing of thin plate of main roof with elastic foundation boundary on both sides of the long side of goaf (coal pillars)," Journal of China Coal Society, vol. 43, no. 12, pp. 3273-3285, 2018.

[39] A. Kutlu, G. Meschke, and M. H. Omurtag, "A new mixed finite-element approach for the elastoplastic analysis of mindlin plates," Journal of Engineering Mathematics, vol. 99, no. 1, pp. 137-155, 2016. 